\title{
Perspective The Origins of Telemedicine and e-Health
}

Rashid L. Bashshur, PhD, ${ }^{1}$ and Mark A. Goldberg, MD Editors-in-Chief Emeritus

${ }^{1}$ University of Michigan Health System, University of Michigan, Ann Arbor, Michigan.

${ }^{2}$ PAREXEL International Corporation, Waltham, Massachusetts.

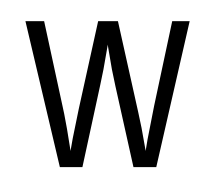

e join the celebration of the 20th year of publication of this journal with a profound sense of pride, the type that parents feel with the success of their offspring acting totally on their own and managing very well. Although the two of us stepped aside from editorial duties at different times, we both left feeling assured the editorship of the Journal would be in good hands, and a solid future of scholarly publications in the ever-growing field of telemedicine and its offshoots would ensue.

The first issue of the Telemedicine Journal (Volume 1, Number 1) was published in the Spring of 1995. It consisted of 83 pages of text, comprising two editorials, one by Mark Goldberg and one by Michael DeBakey, and nine articles. All articles in that first issue, as well as most manuscripts in the remainder of the first volume, were solicited, but all were methodically submitted to peer review. Mark Goldberg was Editor-in-Chief, and Rashid Bashshur and Jay Sanders were Senior Editors (more about this later). We took it upon ourselves to exercise the necessary, at times heavy-handed, editing in the hope that the budding journal would soon be accepted by academics, practitioners, and policymakers as the reliable source for scientific research and scholarly analysis in its field. Hence, it had to meet high publication standards despite the dearth of scientific research in the nascent field of telemedicine at the time. By necessity, this meant an overly active involvement on the part of the editors in shaping the final version of the published articles. It was, in many ways, an entrepreneurial endeavor to get the journal launched, but it was a labor of love.

The first Editorial Board represented a Who's Who in telemedicine at the time, insofar as those with active publication records are concerned. This did not go unnoticed. A book review ${ }^{1}$ in the Journal of the American Medical Association lauded the Telemedicine Journal for the breadth and depth of its content for a variety of readers and for the clinical and technical competence of its Editorial Board. It stated that "The Journal does respond to the informational need posed by telemedicine as it potentially encompasses all aspects of medical practice."

As in many other similar developments, a good idea typically has more than one origin; some get recorded, and some not. The full story of the origins of the Telemedicine Journal is not an exception. Mary Ann Liebert may wish to weigh in and recount when and how the idea for this journal was developed at her publishing company. Her company publishes over 100 journals, and the number keeps growing. But around 1993, there were active discussions between Rashid Bashshur and Jay Sanders regarding the necessity of establishing an independent professional journal as a reliable medium for the exchange of information in telemedicine. These discussions culminated in a concrete plan to establish such a journal, and we agreed on the title as Telemedicine Journal. Upon initial inquiries with people who are knowledgeable in the publication business, it was estimated that a minimum budget of $\$ 150,000$ (equivalent to $\$ 242,718$ in today's dollars) would be needed to sustain the publication for the first few years while operating at a loss, with the expectation that subscription revenue would follow. Several potential sponsors, mostly federal agencies with a serious interest in telemedicine, were contacted in search of commitments.

In parallel, Mary Ann Liebert had also recognized the need and opportunity for a telemedicine journal and had approached Mark Goldberg, then a radiologist at Massachusetts General Hospital, about the launch of a publication and offered him the role of Editor-inChief. Around the time that Jay and Rashid had reached 35\% of their financial target in promises, Mary Ann Liebert called to let me (R.B.) know of her plans and asked me to join her effort. She explained that the solicited funds would not be used, and she would assume all financial and managerial responsibilities for the new publication. Rashid and Jay had both met Mark Goldberg and thought highly of him, and concurred to abandon other plans and join Mary Ann Liebert.

Rashid and Jay were offered the positions of Senior Editors. In late 1995, Rashid Bashshur joined Mark Goldberg as Editor-in-Chief and subsequently as sole Editor-in-Chief from 1995 to 2005. The first volume consisted of four issues annually, and this continued until Volume 10, when we had to publish two large supplements to accommodate the increased volume of accepted manuscripts. The editorial responsibilities were handed over to the capable hands of the current Editors-in-Chief, Ronald Merrell and Charles Doarn.

In addition, to changes in leadership, the Journal went through a variety of other evolutions-along with the field. Sometime in 1996 the Journal was awarded listed status by the National Library of Medicine. This was an important milestone. It was, on the one hand, a credit to the quality of the young publication, but it also served to attract more manuscripts by raising the academic standing of the journal.

In the early years, much of the focus was appropriately directed toward demonstrating the viability of different telemedicine applications-both clinically and from a cost-benefit perspective. In the end, telemedicine is not a field of medicine, but rather a set of enabling technologies and services to deliver care at a distance. The relentless march of technology has served to reduce many of the early 
hurdles while increasing the quality of patient-provider interactions and reducing costs (particularly of telecommunications). Naturally, the role of the Internet and mobile applications has only increased the potential and practicality of telemedicine applications. In recognition of this fact, the Journal was renamed "Telemedicine and e-Health" in 2000. Much of what is today referred to as "m-health" (or mobile health) falls squarely in the telemedicine domain.

From the start our goal was clear-to establish a platform for rigorous academic and scientific discourse on the use of telemedicine to support healthcare delivery and improve lives. It is our sincere hope that Telemedicine and e-Health will continue to contribute to this worthy goal for many years to come.

\section{REFERENCE}

1. Horii SC, Glatt CR. Telemedicine journal. JAMA 1996;275:1365-1366.

Address correspondence to:

Rashid L. Bashshur, PhD University of Michigan Health System

University of Michigan 300 North Ingalls, 8 B 07 SPC 5402

Ann Arbor, MI 48109-5402

E-mail: bashshur@med.umich.edu 